\section{región
sociedad}

Beraud Lozano, José Luis

Interacciones sociedad-naturaleza en Mazatlán, Sinaloa

Región y Sociedad, vol. VIII, núm. 13, enero-diciembre, 1997

El Colegio de Sonora

Hermosillo, México

Available in: http://www.redalyc.org/articulo.oa? $\mathrm{id}=10201304$

How to cite

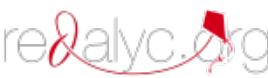

Complete issue

More information about this article

Journal's homepage in redalyc.org

Scientific Information System Network of Scientific Journals from Latin America, the Caribbean, Spain and Portugal Non-profit academic project, developed under the open access initiative 
Derechos reservados de El Colegio de Sonora, ISSN 0188-7408

\title{
Interacciones sociedad-naturaleza en Mazatlán, Sinaloa
}

\author{
Jose Luis Beraud Lozano
}

Resumen:El medio ambiente de la ciudad de Mazatlán,Sinaloa, ha sido radicalmente alterado, al extremo de que sus habitats naturales son reemplazados por artificiales, sin que los habitantes de estos últimos expresen preocupación por preservar algunos elementos característicos de esta concentración espacial que en su etimología significa "lugar de venados" y antaño comprendió maravillosos ecosistemas estuarinos, lagunas, además de hermosas playas.

Muchos de esos recursos han desaparecido o enfrentan el peligro de una grave alteración como consecuencia del carácter de las actividades sociales 0 "externalidades",centradas en la obtención de ganancias a corto plazo, sin que medie una cultura que garantice la preservación de los recursos natura les para su administración sostenida a largo plazo en favor del equilibrio entre los ciclos naturales y la satisfacción de necesidades en las futuras generaciones.

Abstract:The environment of the city of Mazatlán, Sinaloa, has been radically altered, to the degree that its natural habitats are being replaced by artificial ones, and its inhabitants are in the least concerned with preserving some of the characteristic elements of this site, whose name means "place of deer", and that former comprised estuarine ecosystems, lagoons and beatiful beaches.

Doctor en U rbanismo, profesor-investigador de la Universidad Autónoma de Sinaloa, Unidad Mazatlán. Se le puede enviar correspondencia a Luis Castro 129,Fracc. El Toreo, C. P. 82120,Mazatlán,Sinaloa,tel:(69) 84-43-93, c. electrónico beraud@ red2000.com.mx. 
Many of these resources have disappeared or face the danger of severe alterations resulting from the nature of community activities or "externalities" centered in obtaining short term profits, there being no culture for guaranteeing the preservation of natural resources to be managed in a sustained long term fashion, favoring the balance of natural cycles and satisfying the needs of future generations.

\section{Introducción}

En este ensayo las transformaciones espaciales no se consideran como un resultado, sino más bien, como la concatenación de acciones 0 "prácticas" de los integrantes de la sociedad hacia la na turaleza. Esta forma de hacer frente a los acontecimientos puede considerarse de suma importancia, ya que permite conocer los factores reales que a través de la conformación de la ciudad, ejercen impactos temporales o decisivos en la interacción sociedad-naturaleza. Desde esta perspectiva adquiere gran importancia el estudio del proceso, pues así habrá elementos para precisar la dimensión real de semejante interacción.

Si bien es una proposición a demostrar, puede adelantarse que el medio ambiente de la ciudad de Mazatán, Sinaloa, ha sido radicalmente alterado, al extremo de que sus habitats naturales son reemplazados por artificiales, sin que los habitantes de estos últimos expresen preocupación por preservar algunos elementos ca racterísticos de esta concentración espacial que en su etimología significa "lugar de venados" y antaño comprendió maravillosos ecosistemas estuarinos y lagunas, además de hermosas playas.

Muchos de esos recursos han desaparecido o enfrentan el peligro de una grave alteración como consecuencia del carácter de las actividades sociales 0 "externalidades", centradas en la obtención de ganancias a corto plazo, práctica alejada de una cultura que se hubiera preocupado por garantizar la preservación de los recursos naturales para su administración sostenida a largo plazo en favor 
del equilibrio entre los ciclos naturales y la satisfacción de necesidades de las futuras generaciones. ${ }^{1}$

\section{Localización del municipio y ciudad de Mazatlán}

Entre los $105^{\circ} 56^{\prime} 55^{\prime \prime}$ y $106^{\circ} 37^{\prime} 10^{\prime \prime}$ al oeste del meridiano de Greenwich, y entre los paralelos $23^{\circ} 04^{\prime} 25^{\prime \prime}$ y $23^{\circ} 50^{\prime} 22^{\prime \prime}$ de latitud norte, se localiza el municipio de Mazatlán; por extensión (3068.48 $\mathrm{kms}^{2}$ ) ocupa el noveno lugar entre los municipios del Estado de Sinaloa (mapa 1), aunque es de los tres principales en cuanto a concentración demográfica y actividades económicas.

Característica sobresaliente en su ubicación geográfica es la localización en plenoTrópico de Cáncer, cuestión que asegura la caída de rayos solares de muy leve inclinación y determina el predominio de un clima semicálido y semiseco con régimen tropical lluvioso, donde la temperatura media anual oscila entre $24^{\circ} \mathrm{C}$ y $25^{\circ} \mathrm{C}$.

El municipio ubicado al sur del estado de Sinaloa también forma parte de la zona geoeconómica del Mar de Cortés o Golfo de California, viéndose favorecido por una serie de fenómenos naturales que propician condiciones óptimas para la reproducción de algunas especies como el camarón. Cuenta con 80 kilómetros de litoral, a lo largo de los que se constituyen sedimentos arenosos, gravas y conglomerados que forman abanicos aluviales y depósitos de talud.

Merecen particular mención los diversos humedales, lagunas y manglares existentes en el municipio (5,900 has), por conformar ecosistemas de una extraordinaria biodiversidad acuática en que el ecoturismo tiene promisorio futuro. Similar relevancia adquieren

1

Existe, de hecho, una larga historia de interrelaciones entre las ciencias natura les y la economía, (esta) historia aún está por escribirse. Aunque Marx mencionó el mal uso que el capitalismo hacía de los recursos naturales, no le pareció que eso fuera un hecho relevante para explicar la dinámica capitalista",Martínez Alier y Schlüpmann (1991), pp.15-269. 
las principales islas cercanas a la ciudad: Pájaros, Venados, Lobos y de la Piedra.

Por lo que hace a vegetación, el municipio cuenta en la mayor parte de su espacio geográfico con "flora de selva baja" (principalmente "vara" y "estacón", materias útiles para la combustión casera y el cercado), aunque en la costa abundan las especies hidrófilas 0 de manglar. Los árboles frutales constituyen otro recurso importante: mango, cocotero y aguacate son los más valiosos, sin que por ello deba ignorarse la ciruela mexicana, plátano, guayaba, limón, chicozapote y naranja.

Dada la conformación edafológica (suelos) y a partir de la estructuración de los Distritos de Desarrollo Rural, ha sido posible contar con una mayor superficie dedicada al cultivo de frijol, cártamo, sorgo, maíz, chile y pastos, alimento este último imprescindible para el mantenimiento de la ganadería en algunas de las "sindicaturas" o divisiones administrativas que comprende el Municipio (mapa 2).

En relación a la biodiversidad faunística, puede afirmarse que la existencia de cuerpos de agua marinos y ecosistemas terrestres, en otros tiempos hicieron posible que el municipio se caracterizara por una gran variedad de animales como venados, conejos, tigriIlos, pelícanos, patos, garzas, gaviotas, iguanas, víboras, peces, crustáceos, tortugas, aves migratorias, comunidades microbacterianas.

Ahora bien, en la sindicatura central o cabecera municipal el suelo es completamente plano, exceptuando pequeñas elevaciones sobre el nivel del mar como los cerros del Vigía, Nevería, Casama ta, El Crestón, Loma Atravezada y Cerro de la Cruz. "Lo plano del territorio que prácticamente ha sido de relleno y de poca elevación sobre el nivel del mar dificulta el desagüe"; la altitud promedio sobre el nivel del mar es de escasos tres metros, circunstancia por la cual en la época de lluvias gran parte de la ciudad registra inundaciones, dada la coincidencia de las precipitaciones con las mareas altas . 2 
El párrafo anterior plantea algunas interrogantes: ¿Por qué y cómo se produjeron esos rellenos?, ¿qué repercusiones tuvieron los mismos sobre los componentes medio-ambientales? Dependiendo de las respuestas a las preguntas precedentes cha mediado la compatibilidad entre los intereses de las actividades sociales 0 "externalidades" y el potencial reproductor de los ecosistemas locales? Las respuestas deben partir del primer cuestionamiento.

\section{Apropiación del suelo mazatleco}

El soporte físico de lo que actualmente se conoce como ciudad de Mazatlán, en la antigüedad careció de importancia para los asenta mientos humanos, pasando casi inadvertido tanto para las tribus prehispánicas, como para los españoles durante el periodo colonial. Tal irrelevancia obedeció - entre otras circunstancias- al control territorial ejercido, respectivamente, por el "Señorío de Chiametla", la Villa de San Sebastián (Concordia) y el Mineral de Nuestra Señora del Rosario (El Rosario). Por paradójico que llega ra a parecer, este fenómeno contribuyó a preservar la naturaleza en la inhóspita península mazatleca (salvo mención expresa, los referentes históricos fueron consultados en Beraud Lozano 1995).

Todavía durante el primer tercio del siglo XIX, los asentamientos humanos se reducían a la ocupación de una mínima parte del Cerro de la Cruz (barrio "La Chalata", contiguo a la Aduana), mientras que para mediados de siglo empezaba la construcción de viviendas por la zona de lo que ahora se conoce como "centro histórico" de la ciudad (mapa 3).

En aquel entonces la península limitaba hacia el sur con la actual avenida Alemán y existía "un paso de aguas marinas" entre el $\mathrm{Ce}$ rro de la Cruz y tierra firme (rellenado en 1832); aún el cerro El Crestón estaba separado del macizo continenta, situación favorable al libre flujo de corrientes marinas que renovaban constantemente los esteros del Infiernillo, U rías y La Sirena.

Bajo semejantes condiciones la biodiversidad no enfrentaba peligro alguno, razón que explica la abundancia de peces que au- 
nado a la caza de venados, aves, conejos, recolección de frutos y pequeños cultivos, ayudaron a satisfacer las necesidades humanas sin que se alterara la capacidad autorreproductora de la naturaleza. Si acaso, la carencia de agua potable y las epidemias traídas por conquistadores y navegantes, fueron factores adversos a esa "vivencia paradisíaca".

Pero este relato que pareciera haberse extraído de los pasajes de Robinson Crusoe, actualmente no es más que anécdota, en la medida que la naturaleza fue sufriendo los estragos producidos por el tipo de relaciones sociales que iban consolidándose en la formación social mexicana, de la cual Mazatlán sólo es un microcosmos.

Seguramente, uno de los acontecimientos con mayores implicaciones para la sustentabilidad de las relaciones sociedad-naturaleza, fue la apropiación privada del suelo; mediante esta acción, tanto el suelo como sus recursos bióticos pasaron al dominio de unos cuantos habitantes y quedó excluída la mayoría de la población.

Tal vez a corto plazo no era posible advertir los impactos provocados por la apropiación privada del suelo, mas la subsecuente destrucción de los soportes naturales y su transformación en soportes artificiales, nos ayudarán a comprender la dimensión real de las repercusiones de las actividades sociales sobre el medio ambiente.

Durante la segunda mitad del siglo XIX, la interacción sociedadnaturaleza registró una serie de acontecimientos, mismos que por entonces aún no representaban peligro dado el potencial biodegrador y autorreproductor de la naturaleza. Entre los más significativos han de mencionarse los siguientes:

1. Los capitales europeos habían logrado establecer un "enclave comercial importador" en Mazatlán, que se convirtió en la fuerza motriz del acelerado crecimiento de este centro de población;

2. De les consecuencias de este crecimiento, sobresalió la demanda de fuerza de trabajo que pudo satisfacerse con la emigración de habitantes del medio rural hacia la naciente ciudad. Dicho fenómeno generó un incremento demográfico y con ello la ampliación física de la ciudad hasta los límites impuestos por 
la oferta-demanda de terrenos en 1871 (mapa 4). Comparando éste con el mapa 3, logra advertirse que el crecimiento de la ciudad fue produciéndose en perjuicio de habitats naturales ( lagunas, llanos, marismas, entradas de mar, etcétera).

3. A raíz de ese crecimiento espacial, el intercambio energético naturaleza-sociedad comenzó a mostrar ciertas características: los materiales de combustión casera - predominantemente carbón- llegaban de lugares distantes a la emergente concentración mazatleca; los "ojos de agua" de la localidad resultaban insuficientes para satisfacer la demanda social del vital líquido, aunque para 1890 ya se contara con "agua dulce" extraída de los mantos freáticos en "El Pozole", Villa Unión (distante 24 kilómetros).

4. Como cabe suponer, debido al crecimiento demográfico aumentó la emisión de residuos sólidos, líquidos y gaseosos, con los consiguientes impactos medio-ambientales, sobre todo porque el Ayuntamiento no tenía capacidad para controlarlos. Baste recordar relatos acerca de la inmundicia alrededor del mercado - actual Plaza República- 3 e imaginar las consecuencias que para la salud humana producía el hacinamiento de una población obligada a vivir en "cuarterías" (espacio en que sin división alguna se realizaban todas las actividades del hogar), donde los servicios sanitarios se suplían con fosas sépticas de fácil descarga y contaminación hacia los mantos freáticos;

5. Todavía más significativos que la emisión residual de las viviendas, fueron los desechos sin control alguno de la pujante ma nufactura, descargados a la Bahía del Fondeadero (hoy Playa Sur) u Olas Altas: la Fundición Sinaloa, la fábrica de hilados y tejidos "La Bahía", la fábrica de cigarros y puros "El Dios del Amor", la tenería y curtiduría de los Coppel, las manufacturas de fósforos-hielo y muebles de Felton Hnos., la construcción de lanchas y barcazas por Careaga Hnos. y la familia Medrano. Unicamente la capacidad biodegradadora de la naturaleza ayuda a explicar que desde entonces no se produjera la destrucción de algunos elementos del medio ambiente. 
6. A los casos mencionados hay que agregar la primera construcción del puente sobre la desembocadura del estero El Infiernillo al Canal de Navegación (finales del siglo XIX); con esta acción promovida por los comerciantes importadores y ejecutada por el régimen porfirista, se pretendió solucionar un importante obstáculo para la distribución mercantil, sin haber previsto las repercusiones que ello provocaría a la flora y fauna acuáticas del estero, por la disminución del área hidraúlica de desfogue.

Otra ampliación en 1906 no hizo más que agravar un problema que a la fecha muestra el azolve y muerte de la biodiversidad en ese cuerpo de agua; de los $240 \mathrm{~m}$ que originalmente tenía la desembocaduratentrada de agua de mar, hoy la anchura está reducida a 40 metros, y lo más preocupante es que no se mantiene desazolvada la salida.

En dinámica contradictoria del "progreso urbano" que destruye para transformar, hay que registrar la "rebanada" que experimentó el Cerro de la Nevería para el Paseo Claussen; la obra hizo posible que los mazatlecos y los visitantes contaran con un lugar desde donde los atardeceres resultan inolvidables. Tal vez esta sea la compensación por haber afectado uno de los elementos de la naturaleza.

\section{Avance de la destrucción y transformación de la naturaleza}

Pero, realmente, las acciones de destrucción y transformación de la naturaleza fueron intensificadas en el transcurso del siglo XX;las mismas pueden caracterizarse en función de la directa vinculación que guardan con las actividades económicas 0 externalidades asignadas a Mazatlán por la inversión privada y las políticas públicas. En este contexto, la importancia de los recursos naturales ha sido determinante, dado que los soportes materiales (playas, puerto) y los recursos bióticos (pesca), propiciaron la instauración de particulares procesos de obtención de ganancias. 
Contar con la bahía-ensenada de Puerto Viejo o Bahía de San Fé lix (hoy Playa Norte), fue el principal argumento expuesto ante las Cortes Españolas cuando se solicitó convertir a Mazatlán en puerto de altura en $1804 ; 4$ tuvieron que transcurrir más de cien años para que esa aspiración empezara a cobrar realidad. De nada había servido cambiar el área de desembarque a la Bahía del Fondeadero (Playa Sur), debido a que el movimiento portuario continuó operando con métodos e infraestructura anacrónicos.

Correspondió al gobierno de Lázaro Cárdenas emprender la construcción del puerto mazatleco, acción prolongada hasta 1970; sin temor a equivocación, puede afirmarse que mediante estos tra bajos, simultáneamente se destruye y transforma la naturaleza, ya que los recursos bióticos de un cuerpo de agua marina experimentaron completa alteración.

Poco a poco fueron rellenadas más de $\mathbf{5 0}$ hectáreas de aguas marinas al sur de la hoy avenida Alemán y con los rompeolas de la Isla del Chivo a Isla de la Piedra y del Cerro del Crestón a tierra firme, el ecosistema acuático natural quedó reemplazado por un habitat artificial, donde la lógica dominante ya no estaría definida por la regulación homeostática, sino por el apetito de plusvalía del capital inmobiliario y los intereses estatales expresados en la construcción de un fraccionamiento privado, muelle fiscal, dragados del puerto (canal, antepuerto y dársenas), accesos ferroviarios y carreteros, terminal abastecedora de PEMEX, terminal de transbordadores, almacenes, patios, oficinas 5

Mas no únicamente han de destacarse los impactos ambientales derivados de las obras del puerto, también son significativas las consecuencias que trajo su operación, en la medida que con el incremento del tráfico marítimo las aguas del Canal de Navegación desde entonces reciben desechos de transbordadores, barcos mercantes-petroleros y turísticos, flota deportiva, además de aceites, grasas, óxidos y otros materiales del mantenimiento de la flota ca maronera atunera.

Héctor R.Olea (1980), p. 231.

5 Secretaría del Patrimonio Nacional (1975), p. 215. 
Aunado a los impactos ambientales ocasionados por la construcción-operación del puerto, merece registrarse la sobreexplotación de los principales recursos bióticos de Mazatlán como son los pesqueros. Por distintas fuentes se conoce que la captura de especies marinas ha representado una actividad fundamental para los habitantes de la localidad; después de practicarse en forma libre la captura y venta de especies de escama y camarón, paulatinamente los pescadores libres fueron desplazados por japoneses y enseguida por armadores, quienes acumularon cuantiosas fortunas mediante la sobreexplotación de recursos marinos y de la fuerza de trabajo.

No obstante encontrarse ubicado Mazatlán en "un área de afloramiento muy importante (Golfo de California) donde la productividad fitoplanctónica es muy elevada ahí por darse un ciclo de gran amplitud, que repercute en gran abundancia de biomasa", 6 la ausencia de métodos y prácticas conservacionistas, han terminado por impactar negativamente ese potencial biótico, ya sea en esteros, lagunas o en la plataforma continental. Debido a esta lógica irracional, hoy la pesca ha perdido relevancia en cuanto actividad generadora de ganancias y como sector ocupacional de la fuerza de trabajo.

Otro de los recursos que llaman a la reflexión por los impactos ambientales producidos a consecuencia de las externalidades dominantes, son las playas. A pesar de que únicamente un tercio del litoral de la ciudad mazatleca ha atraído la inversión de capitales, la construcción de hoteles, vialidades y emisión residual (basura, aguas negras, grasas, bronceadores, ruidos), contribuyeron a erradicar una rica biodiversidad: iguanas, víboras, aves, roedores, venados, conejos, hongos, flora y numerosas comunidades microbacterianas.

Además de los casos señalados en que se evidencia la destrucción de ecosistemas naturales y su reemplazo por un habitat artificial, hay otros factores 0 "externalidades" que también deben ser mencionados por el impacto ambiental que han venido generando. 
A partir de su instalación, procesadoras de alimentos marinos, talleres del parque industrial Bonfil, la termoeléctrica, la planta distribuidora de Pemex,los talleres del ferrocarril, estuvieron ope rando sin haber establecido controles de sus residuos, al extremo de que hasta hace apenas unos meses, el fétido olor de las guaneras y los humos de la termoeléctrica eran la primera impresión pa ra quienes arrivaban a la ciudad por el acceso del sur.

En este mismo contexto, hay que registrar la elevada contamina ción del llamado Canal de Pemex, afluente a donde van a parar las descargas de empreses privadas, Pemex y el Ferrocarril del Pacífico Norte, así como el drenaje habitacional de varias colonias populares, situación que repercute directamente en los elevados índices de contaminación de los esteros de Urías y La Sirena, según lo confirman estudios de investigadores universitarios y numerosas declaraciones de la Secretaría de Marina, la Capitanía del Puerto, el Consejo Ecológico de Mazatlán, el Departamento de Ecología del Ayuntamiento y la Procuraduría Federal de Protección al Ambiente. ${ }^{7}$

Mas el problema del Canal de Pemex no se reduce a la contaminación ambiental, sino al constante peligro de incendios en la temporada de estiaje, como resultante del elevado contenido de hidrocarburos en las descargas vertidas al Canal, fenómeno que por cierto, ha ocurrido en años anteriores.

En base a la información hasta aquí apuntada, es posible sostener que el medio ambiente mazatleco ha sufrido una profunda alteración, afectando directamente a sus habitantes y ecosistemas naturales; como quedó asentado en varios párrafos, semejante panorama fue agudizándose paralelamente al crecimiento de la ciudad. Pero por si quedaran dudas respecto a esta conclusión, recurrimos a otras evidencias que aporta la conformación de la ciudad mazatleca.

$7 \quad$ En escasos correctivos se han traducido todas esas denuncias y se ha llegado al extremo de que el encargado del Departamento de Ecología del Ayuntamiento denuncie los obstáculos burocráticos de autoridades federales que impiden contener la destrucción de los cuerpos de agua que rodean a la ciudad de $\mathrm{Ma}$ zatlán,( 1996), N oroeste, (Nuestro Ambiente), septiembre. 


\section{Impacto ambiental del crecimiento de la ciudad}

Líneas arriba se ha mencionado que en la segunda mitad del siglo XIX, Mazatlán adquirió una destacada importancia geo-económica como consecuencia de la concentración de actividades productivas y fuerza de trabajo, subordinadas al capital europeo. Pero la ciudad no crecía dada la resistencia de los propietarios del suelo a vender lotes, pues permanecían a la espectativa de mejores tiempos para incrementar las ganancias.

Entre tanto, se concretaron a construir vecindades en un espacio que desde 1871 hasta 1930, estuvo limitado por la calle Tiradores (Zaragoza) al norte, la calle Casa Mata al este, la Calle del Ciprés al sur, al poniente la calle de Peñuelas, la zona residencial de OlasAltas y el actual Centro Histórico (ver mapa 4). Más allá de los límites por el norte y el este, sólo había llanos, lagunas y esteros, conformando ricos ecosistemas en donde la biodiversidad se advertía en la gran cantidad de animales y vegetación terrestre-acuática.

Si acaso la actual colonia Esperanza, parte de las colonias Montuosa, Casa Redonda y algunos ejidos (Urías o El Venadillo) eran asentamientos que invitaban a los intrépidos a viajar desde el centro con la posibilidad de observar venados, conejos, patos, garzas, árboles frutales,caballos, pastizales; algunos de estos recursos bióticos desempeñaban una importante función alimenticia directa para los habitantes.

Sin embargo, este panorama medio-ambientalista registró un cambio acelerado a partir de la década 1950-60;durante este periodo la cabecera municipal registró la máxima tasa de crecimiento anual de su población (5.5\%), consolidando así la tendencia de la concentración urbana que ya había destacado el urbanista Luis Unikel8 (cuadro I-A1), donde Mazatlán aparecía en 1900 como la principal ciudad del Noroeste. 
Mas el aumento de habitantes no correspondía a la oferta de vivienda, situación que orillaba a los trabajadores a emprender acciones desesperadas ante el hacinamiento de que eran objeto. Por entonces, varios propietarios del suelo decidieron vender lotes y el Estado procedió a expropiar "haciendas" en la parte norte del estero El Infiernillo, con el fin de repartirlas entre los cientos de solicitantes de vivienda.

Bajo la concatenación de semejantes acciones surgía la colonia Benito Juárez y se daría paso a la construcción de los multifamiliares al sudoeste del estero El Infiernillo, área de inicio de las invasiones populares que dieron origen a las colonias Estero e Independencia (1960). La civilización del concreto arrasaba arbustos y pastizales para que apareciera la colonia López Mateos (1962) y ya en la década de 1970, el balance ambiental resulta negativo para los habitats naturales que iban desapareciendo ante el embate del crecimiento de la mancha urbana, en la medida que la biodiversidad sufría las consecuencias de una civilización en que sus clases dirigentes tienen como interés inmediatista y prioritario la acumulación de ganancias, sin que hubieran adoptado medidas para mantener el equilibrio entre las necesidades sociales y la conservación-reproducción de los recursos naturales.

Pero no nada más la devastación de ecosistemas permite corroborar la destrucción de habitats naturales y su reemplazo por cientos de casas, miles de metros cuadrados de asfalto-concreto (con las consiguientes contribuciones para el sobrecalentamiento y contaminación atmosféricas). También las emisiones residuales sin control empezaron a producir impactos sobre el medio ambiente, afectando así la posibilidad de reproducción equilibrada de los recursos bióticos (incluído el hombre). Veamos algunas casos:

1. Por relatos históricos conocemos que el estero El Infiernillo constituyó un ecosistema riquísimo en especies acuáticas (flora y fauna), que experimentó constante renovación a través del flujo permanente de las mareas que por el Canal de Navegación penetraban cotidianamente. Conforme fue creciendo Mazatlán "el vaso" del estero se convirtió en receptor de aguas negras sin 
tratamiento alguno, provenientes de la colonia Juárez y asentamientos contiguos que aparecieron en la ribera.

$\mathrm{Si}$ a lo anterior agregamos el azolve ocasionado por los arrastres depositados en su seno por arroyos (principalmente El Jabalines) y la restricción del área hidráulica que provocó la construcción del puente Juárez en tiempos del porfiriato (el ancho de la desembocadura se redujo de 240 a $40 \mathrm{~m}^{2}$ ), podemos concluir que el azolvamiento y la contaminación rebasaron la capacidad biodegradora en este cuerpo de agua, de tal suerte que su muerte no es consecuencia de causas naturales, sino resultado de un crecimiento urbano anárquico alejado de toda consideración respecto a la necesidad de mantener la sustentabilidad del desarrollo entre sociedad y naturaleza.

El extremo de semejantes acciones irracionales estuvo a cargo del Estado Mexicano que con el pretexto de "regenerar el estero", desincorporó $1,371,469 \mathrm{~m}^{2}$, en favor del Municipio. ${ }^{9}$ Para las autoridades del Ayuntamiento la "regeneración" pareció haberse reducido a la recuperación de "tierras ganadas al mar", 10 posponiendo la efectiva e integral recuperación de tan importante ecosistema natural, que de sus 381 hectáreas originalmente cubiertas de agua, hoy sólo quedan 96 hectáreas de aguas contaminadas. ${ }^{11}$

Decreto del Gobierno Federal (1982), noviembre.

10 Estas acciones contenidas en el Plan Parcial de Regeneración del estero El Infiernillo (1984-86) más que estar dirigidas a la recuperación del cuerpo de aguas, fueron concebidas bajo la mentalidad de aumentar las reservas territoriales del Municipio. El descifrado de ellas no deja lugar a dudas:1) Construcción de terraplenes 0 bardas para delimitar lo que será un lago artificial de 120 mil $\mathrm{mts}^{2}$; 2) Construcción de un puente en la sección media del estero para desfogar libremente las aguas del Arroyo Jabalines;3) Dragado y relleno del estero en una cantidad de 2.5 millones de $\mathrm{mts}^{3}$; 4) Regularización de la tenencia de la tierra;5) Definición de usos del suelo en la superficie ganada mediante rellenos; y 6) Urbanización de calles, avenidas y áreas verdes.

11 Nuevamente en 1994 se realizaron estudios para lograr la regeneración de lo poco que queda de un cuerpo de aguas que al inicio del siglo XX constituía un atractivo maravilloso, además de ser habitat de especies que contribuían a resolver parte de las necesidades alimenticias de algunos sectores de la población mazatleca. En esta perspectiva el Departamento de Ecología del Ayuntamiento 
2. En el caso de los residuos líquidos no queda más que reconocer la gran capacidad biodegradadora existente en los cuerpos de agua marina, pues las descargas del sistema anacrónico del drenaje municipal se han lanzado indiscriminadamente a lagunas, esteros y playas. Dicha situación permite localizar áreas de elevada contaminación (detectadas por los frecuentes monitoreos de la Octava Zona Naval) como son la desembocadura del estero El Infiernillo en el Puente Juárez, el Parque industrial Bonfil, el Rastro Municipal y frente a la termoeléctrica.

Al mencionar la contaminación por descarga de aguas negras, es necesario mencionar a la Junta Municipal de Agua Potable (Jumapam) que en varias ocasiones ha descargado aguas negras sin tratamiento alguno al estero El Infiernillo (datos de la propia Jumapam), 12 provocando contaminación y muerte de peces y organismos marinos por hypoxia o falta de oxígeno. ${ }^{13}$

Aunque Mazatlán cuenta con una planta tratadora de aguas negras (instalada al pie del cerro El Crestón), mínima ha sido la utilidad de ese "elefante blanco", en la medida que continúan arrojándose al mar las aguas sin un tratamiento completo, las que por efecto de las mareas y la inadecuada distancia del colector submarino, regresan a "bañar" parte del litoral y prorratear su cuota de coliformes a cada bañista. Desde mediados de 1996 a la fecha las aguas negras son descargadas sin tratamiento alguno, pues supuestamente se le iba a dar mantenimiento al "elefante blanco"; esta situación fue identificada como una de las causas que produjo mortandad de peces en el mes de abril de 1997.14

ha venido proponiendo "ampliar de 40 a 165 metros la boca del estero", № roeste (1993), abril.

12 |bid

13 Isidro Osuna et al. (1993).

14 A finales del mes de agosto de 1997, fueron asignadas las obras de regenera ción de la planta tratadora de aguas negras; pero resulta que por el presupuesto insuficiente, únicamente podrán realizarse trabajos para el tratamiento primario (construcción de desarenador, rastras y caja derivadora), cuando la re- 
3. La producción de $\mathbf{4 0 0}$ toneladas diarias de basura representa otro de los serios peligros contra el medio ambiente mazatle co; hasta 1992, los residuos sólidos eran depositados a "cielo abierto" en el ejido Rincón de Urías (oriente de la ciudad), y se sostenía que no constituía un peligro para la sociedad y los ecosistemas. Pero ¿qué pasaba con las humaredas de la incineración rudimentaria aplicada durante largo tiempo?, ¿qué ocurría con los escurrimientos cotidianos de la putrefacción de la materia orgánica o los provocados en temporada de lluvias? Estas interrogantes no se formulan por simple ocurrencia, sino porque dichos escurrimientos contaminan los mantos freáticos interconectados con los esteros de U rías y La Sirena.

Pareciera que los impactos ambientales negativos que se generan a causa de este tipo de residuos van a controlarse en función del "relleno sanitario" que dió inicio en 1993,después que la ex-SEDUE incluyó a Mazatlán en el Plan Piloto correpondiente, bajo apoyo crediticio del Banco Mundial. Mas esa solución ya provoca algunos temores: resulta que por las elevadas temperaturas en la región, la descomposición de la materia orgánica está generando gases que son causa de fuertes explosiones que escuchan vecinos de colonias populares como la Fe lipe Angeles y La Sirena.

El "relleno sanitario" no resuelve del todo la contamina ción producida por la basura, si no va acompañado del recicla je. Por esta razón es preocupante el hecho de que no obstante que empresas extranjeras han solicitado hacerse cargo de la se paración de la basura, no hay respuesta oficial sobre el particular. Debido a estas circunstancias puede advertirse que de no ser atacado integralmente el problema de residuos sólidos, la emisión de gases (con peligro de explosiones), los escurrimientos por putrefacción, la proliferación de roedores y todo tipo de

comendación técnica exige complementarlo con la fase secundaria y terciaria, lo cual contribuiría a obtener aguas sin peligro alguno para los ecosistemas. Estas obras han sido calificadas por varios especialistas como "el mejoral que se receta a un enfermo en fase terminal", Noroete (1997), "Nuestro Ambiente", septiembre. 
insectos éstos van a seguir representando un serio peligro para los asentamientos populares y el resto de los componentes medio-ambientales de la ciudad.

4. No obstante que la ciudad es beneficiada por la brisa y corrientes de aire, el parque vehicular opera como principal emisor de humos que parecieran no perjudicar a la biodiversidad. Si los habitantes no alcanzan a percibir la gravedad del problema, precisa recordar que todos esos gases (monóxido y bióxido de carbono, bióxido de nitrógeno, bióxido de azufre, partículas suspendidas totales - pst- ), contribuyen a dañar la biósfera. Para quienes pudieran atreverse a sostener que este tipo de contaminantes no afecta a la ciudad de Mazatlán, bastaría con invitarlos a caminar por las calles de congestionamiento vehicular a las horas pico, para comprobar que de no ser por la localización privilegiada del puerto, sus habitantes ya estarían sufriendo los impactos inmediatos que en las grandes concentraciones urbanas se padecen.

Y es que autobuses del servicio urbano, autos particulares, motocicletas y otros medios del transporte accionados por derivados del petróleo, además de tener que usar hidrocarburos de baja calidad, son descuidados en su mantenimiento ante la ausencia de cultura ambiental y la complacencia de las correspondientes autoridades que no aplican la normatividad ecológica del Municipio, el Estado y la Federación.

Acreedora a una mención particular en el caso de la emisión de humos y aguas con temperaturas superiores a las prevalecientes en el cuerpo acuático del ecosistema estuarino La Sirena-U rías,es la Comisión Federal de Electricidad.Cotidianamente la termoeléctrica operada por esa paraestatal emite enormes cantidades de ambos residuos. $Y$ aunque los responsables de la operación buscan persuadir de que no $s$ están provocando deterioros ambientales,el uso diario de 3 millones cien mil litros de combustóleo es un factor que a la fecha impide eliminar los impactos negativos, a pesar de las inversiones y esfuerzos realizados. También los estudios de biólogos y químicos advierten sobre la presencia de materiales y "aguas pesa das", que tal vez por simple coincidencia se hallan en los humedales contiguos a la empresa. 
5. Un tipo de contaminante poco estudiado en la localidad es el ruido; particularmente significativo es el funcionamiento de aparatos electrónicos en unidades de transporte urbano, comercios, centros nocturnos, eventos musicales y en las propias casas particulares. En todos esos casos, la capacidad de percepción auditiva está amenazada por el enrarecimiento de las condiciones ambientales para cualquier organismo vivo, dado el aumento desmedido del volumen, que llega al extremo de que en algunos espacios pareciera estarse compitiendo por demostrar la supremacía a través del incremento de decibeles. Obviamente que de esta carrera absurda también se derivan impactos para la biodiversidad, debido a los efectos sensoriales que provocan los aparatos musicales.

6. En Mazatlán, adquiere significativa relevancia la colocación de una gran cantidad de anuncios que rompen con la armonía de los paisajes naturales De esta forma y sin que se tome conciencia de dicho fenómeno, la percepción cotidiana es testigo pasivo de una particular modificación de los elementos de su medio ambiente.

\section{Alcances de la sustentabilidad a través de la reorientación del desarrollo urbano en la ciudad y municipio de Mazatlán}

Por los elementos hasta ahora expuestos, la preocupación de las sociedades contemporáneas para hacer compatible la satisfacción de las necesidades sociales con la conservación de los recursos y los ciclos reproductivos de la naturaleza, en el caso del medio ambiente mazatleco no parece muy consistente, pues a excepción de honrosas manifestaciones aisladas, no existen amplias expresiones de preocupación entre los distintos sectores de la población por el reencuentro con la naturaleza.

¿Lo anterior implica que es irreversible la destrucción del medio ambiente mazatleco? De ninguna manera, pues el juicio corresponde al estudio científico de la situación, que no es producto del 
simple escepticismo o de una visión catastrofistal apocalíptica. A partir de esta distinción, puede afirmarse que la ciudad y municipio de Mazatlán están en posibilidades de recuperar un cierto equilibrio entre las necesidades del desarrollo social y las necesidades reproductoras de los elementos naturales, garantizando así el futuro de las próximas generaciones humanas y la biodiversidad regional.

En esa perspectiva, adquiere carácter prioritario la generación de conocimientos y cambio de actitudes para favorecer la interacción sociedad-naturaleza, ya que de no mediar una cultura ambiental, las posibilidades del desarrollo sostenido se nulifican, tal y como ha sido reconocido desde la Conferencia Intergubernamental sobre Educación Ambiental celebrada en Tbilisi (ex-URSs, 14 al 26 de octubre de 1977), preocupación refrendada por el Banco Mundial, la Cumbre de la Tierra y la propia legislación ecológica de nuestro país.

¿Cuál es la razón de asignar prioridad a la adquisición de conocimientos y cambio de actitudes en una ciudad y municipio como Mazatlán?Ya en el inciso 2 de este ensayo quedó registrada la localización geo-económica privilegiada del municipio en un ecosistema como el Mar de Cortés. Como se señaló en su momento, esta ubicación determina que el municipio cuente con recursos naturales de alta potencialidad para el desarrollo de actividades socio-económicas.

Sus playas son seguramente, uno de esos recursos de extraordinario valor, ya que a las opciones hasta ahora ofrecidas en los desarrollos turísticos, debe agregarse el potencial del litoral que abarca el municipio y se prolonga hacia San Blas, Nayarit, conformando ecosistemas en que flora, fauna, corrientes marinas, arenas, temperatura, hacen de los escenarios naturales una realidad muy rica.

Dentro de esta realidad conviene destacar los numerosos humedales existentes en esa demarcación geográfica, fenómeno que se convierte en un atractivo de enorme importancia para el desarrollo de rutas ecoturísticas, donde los paseantes pueden disfrutar de las experiencias y vivencias inolvidables que dejan los recorridos 
por los diversos sistemas estuarinos ricos en camarón, aves multicolores, peces, anfibios, animales terrestres y exuberante vegetación.

Algunas de estas especies aún es posible encontrarlas en el espacio municipal, aunque lamentablemente habitats como el del sistema estuarino Urías-La Sirena-Isla de la Piedra-Barrón requiere de la acción urgente de los sectores sociales para evitar una alteración irreversible.

Y ya que se destaca la potencialidad de los recursos naturales, también es oportuno señalar que la ciudad de Mazatlán cuenta frente a sus playas con algunas islas, dentro de las que por su ta maño e importancia como habitats de reproducción de flora y fauna (especialmente el pelícano café), merecen mencionarse las de venados, pájaros y lobos. Pero a éstas no únicamente les da relevancia el tamaño y el ser habitat de especies en desaparición, sino que en sus orillas también puede capturarse una enorme variedad de peces y moluscos 0 tra cualidad de esos espacios conocidos como las "Tres Islas" es su valor estético. ¿Acaso todas éstas no son razones de peso para realizar esfuerzos con el fin de conservar este patrimonio de los mazatlecos y de la humanidad?

Este ensayo ha incluído la mención de las numerosas lagunas y esteros que hasta el siglo pasado hubo en varias partes de lo que hoy es la ciudad de Mazatlán; lamentablemente el relleno, azolvamiento y contaminación de varias de ellas, han producido su desaparición. En el caso de las lagunas, la del Camarón es un caso que amerita la movilización de autoridades, empresarios y ciudadanos; ella es depositaria de descargas directas de drenaje y basura de negocios contiguos. De ser un cuerpo de agua en el que abundaban peces y llegaban garzas, patos, pelícanos, flamingos, actualmente se registran elevados niveles de contaminación según estudios del Departamento de Ecologia Municipal y del Consejo Ecológico de Mazatlán.

La Laguna del Camarón constituye un verdadero reto para la sociedad mazatleca: 0 se deja a la inercia del desdén hasta llegar a su destrucción completa o se busca su recuperación integral, como una opción en que es posible establecer actividades para el conocimiento y esparcimiento de habitantes y turistas. ¿Podemos imaginar lo que provocaría en niños, jóvenes y adultos la convi- 
vencia en un medio favorable a la vida de peces y al arribo de aves, además del disfrute de la vegetación? Ojalá que el valor de la vida se imponga a las tendencias destructoras de los elementos de nuestro medio ambiente.

Aspiración semejante a la anterior es la que se puede formular con lo que queda de los esteros; en el caso del Infiernillo nueva mente se intenta recuperar el equilibrio natural en lo poco que queda de su extensión original. El sistema estuarino U rías-La Sirena-Canal de Navegación requiere de acciones determinantes para contener la elevada contaminación que registra; en el del Sábalo es necesario reconstruir algunos de sus procesos naturales, después de las graves alteraciones que han producido las obras de los megaproyectos turísticos ahí establecidos.

Es oportuno recordar que este último lugar estaba convertido en un santuario de aves migratorias que hacían recorridos desde Canadá y Estados Unidos hacia Centro y Sudamérica y viceversa.Ahí también había oportunidad de saborear un pescado fresco extraído de las aguas del estero, 0 en época de camarones era posible disfrutarlos al estilo del cliente, siempre a la sombra de una frondosa amapa, un guamúchil o el impactante contraste del verde del follaje y el naranja de las flores del tabachín. Todo eso desapareció, esperando que las nuevas actividades económicas logren establecer otra forma de equilibrio con la naturaleza.

Pero no todo está perdido, ya que la función de santuario que las aves migratorias habían asignado al estero del Sábalo, actualmente ha sido desplazada al estero de La Escopama, cercano al hotel más alejado del centro de la ciudad.

La flora y fauna terrestre son otros casos en que se hace necesario que población local y turistas valoren la importancia de conservarlas, como recursosútiles para la satisfacción de necesidades humanas, incluída la del esparcimiento. El municipio cuenta con variadas especies, de tal forma que en los recorridos por cada una de las sindicaturas aún es posible disfrutar de la biodiversidad tan pródiga en nuestro país.

El municipio y ciudad de Mazatlán cuentan con una gran variedad de recursos naturales; racionalizando su explotación es posible reestablecer un cierto equilibrio entre la satisfacción de las necesi- 
dades sociales presentes y futuras, con la dinámica reproductiva en los ecosistemas naturales.

En este sentido, Mazatlán todavía está a tiempo de revertir algunos de los fenómenos que amenazan convertirse en graves problemas ambientales. Aunque son ejemplos aislados, ya hay indicadores de que existen sectores sociales que han comprendido la necesidad de controlar los factores negativos que generan altos índices de contaminación.

Empresas como Pemex y el ferrocarril del Pacífico-Norte han introducido algunos controles de sus emisiones contaminantes; tendencia similar se advierte en una que otra empresa privada que ya cuenta con desarenadores, cribas, trampas de aceite y grasas. En varias partes de la ciudad, los pobladores separan la materia orgánica y la inorgánica, aunque cuando llega el camión recolector de basura procede a la mezcla indiscriminada.

En las colonias populares, la plantación de árboles es una acción altamente estimada. En estas circunstancias, la educación ambiental en las escuelas y otras formas de educación acerca del valor de la naturaleza, ayuda a recobrar cierto optimismo respecto del reencuentro de los hombres con su medio ambiente.

Las propias políticas gubernamentales (niveles federal, estatal y municipal) están contribuyendo a la toma de conciencia y cambio de actitudes Fue, precisamente, desde el campo de dichas políticas de reordenamiento territorial, donde parecieron surgir condiciones para propiciar la conservación de espacios ante el anárquico crecimiento que había caracterizado la expansión de la "mancha urba na" en la cabecera municipal.

Con la aprobación y aplicación del "Plan Director de Desarrollo Urbano" de Mazatlán (1991), 15 así como del Reglamento de Protección al Medio Ambiente para el Municipio de Mazatlán (1993), se buscaba regular el crecimiento de la ciudad; el hecho de que la aplicación de la normatividad urbana y la ambiental dependieran 
de la Dirección de Planeación, daba una pequeña esperanza para que en lo sucesivo la conformación de la ciudad no atentara contra los ecosistemas naturales.

Pero el optimismo resultó efímero, ya que los propios funciona rios responsables de hacer observar la ley, han reconocido su impotencia ante las presiones privadas 0 de sectores sociales que invaden zonas reservadas para el equilibrio ecológico, con lo cual buscan modificar los usos de suelo para adecuarlos a sus respectivos intereses.

Por esta sencilla razón es de reiterar la necesidad de consolidar conocimientos y propiciar el cambio de actitudes favorables a la conservación de los elementos del medio ambiente, pues es una de las formas que pudiera resultar más eficaz para lograr que en el crecimiento urbano de Mazatlán adquiera prioridad el reencuentro con la naturaleza. Esta conclusión es todavía más terminante, cuando la concentración demográfica y las actividades predominantes están directamente vinculadas a los recursos naturales de la región.

De la misma manera a como se están recuperando las bellezas arquitectónicas del Centro Histórico de la Ciudad, es posible afirmar que la recuperación de las bellezas naturales del Municipio, justifica todos los esfuerzos que se puedan emprender para beneficio de las presentes y futuras generaciones, así como de la conservación de nuestros recursos naturales.

\section{Bibliografía}

Beraud Lozano, José Luis (1995), Actores Históricos de la Urbanización Mazatleca, Culiacán, México, Difocur.

Gobierno del Estado de Sinaloa (1985), M unicipio de M azatlán,Síntesis Monográfica, Culiacán, México, Secretaría de Hacienda Pública y Tesorería. 
(1991), "Plan Director de Desarrollo U rbano de Maza tlán, 1989-2000", Diario Oficial El Estado de Sinaloa, Culiacán, México, tomo LXXXIII, 2a época, 4 de febrero, Secretaría General de Gobierno.

(1993), "Reglamento de Protección al Medio Ambiente para el Municipio de Mazatlán", Diario Oficial El Estado deSina Ioa, Culiacán, México, tomo LXXXIV, 2a época, 22 de diciembre, Secretaría General de Gobierno, Culiacán, México.

Instituto Nacional de Estadística, Geografía e Informática - INEGI(1986), Anuario Estadístico del Estado de Sinaloa, México.

(1991), Sinaloa: Resultados Definitivos, XI Censo General de Pobla ción y Vivienda 1990, México.

Leff, Enrique (coord.) (1986), Los problemas de conocimiento y la perspec tiva ambiental del desarrollo, México, Siglo xxı Editores.

(1990), Medio ambiente y desarrollo en México, México, Centro de Investigaciones Interdisciplinarias en Humanidades, vol. 2, UNAM, p. 376-766.

Martínez Alier, Joan y Klaus Schlüpmann (1991), La Ecología y la Eco nomía, México, Fondo de Cultura Económica.

Olea, Héctor R. (1980), Los asentamientos humanos en Sinaloa, Culiacán, México, U niversidad Autónoma de Sinaloa.

Pearce, DavidW. (1985), Economía ambiental, México, Fondo de Cultura Económica, trad. Eduardo L. Suárez.

Salinas Chávez,Antonio (1991), "Sinaloa: los límites de la prospe ridad económica", Comercio Exterior, vol. 41, no. 10, octubre.

Sánchez Hidalgo Villalobos, Joaquín (1959), M azatlán de antaño, (Ve nadolandia), México, 2a edición, (corregida, aumentada y editada por su autor), México. 
Secretaría del Patrimonio Nacional - Sepanal- (1975), Plan Direc tor de Desarrollo Metropolitano Mazatlán 1975, México, Comisión Coordinadora de Puertos.

Unikel, Luis (1976), El desarrollo urbano en México:Diagnóstico e implica ciones futuras, México, Centro de Estudios Económicos y Demográficos, Colegio de México. 
